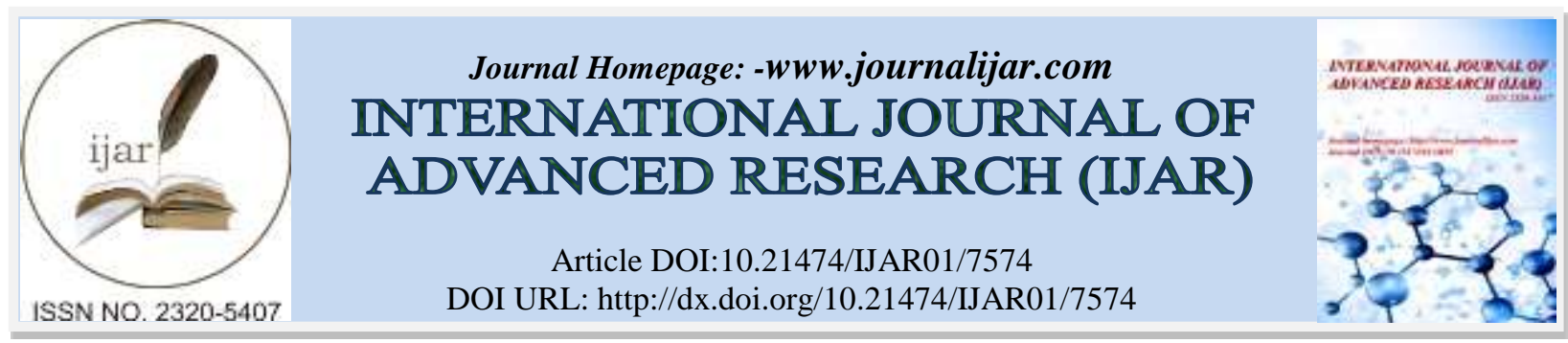

RESEARCH ARTICLE

\title{
SYSTEM COMPARATIVE ANALYSIS FOR PREDICTING GAS HYDRATE FORMATION.
}

Okologume Chinedu Wilfred ${ }^{1}$ and Appah Dulu ${ }^{2}$.

1. Department of Petroleum Engineering, Federal University of Petroleum Resources, Effurun, Nigeria.

2. Department of Petroleum and Gas Engineering, University of Port Harcourt, Port Harcourt, Nigeria.

\section{Manuscript Info}

\section{Manuscript History}

Received: 16 June 2018

Final Accepted: 18 July 2018

Published: August 2018

Keywords:-

correlation, hydrate, flowline, prediction, flow assurance.

\section{Abstract}

Gas hydrates pose one of the major flow assurance problems in natural gas production, field processing, and distribution. In order to militate against the costly intervention and the downtime resulting from treating hydrates, it is expedient to have an effective strategy of predicting the conditions at which they are formed. Various methods have been used in time past to predict hydrate formation conditions; such includes the vapour-solid equilibrium ratio as proposed in the Katz gravity method, the John modified k-factor method, and empirical correlations. In this study, a systematical approach is used to carry out a comparative analysis of existing correlations for predicting hydrate formation conditions, and to determine the suitable method to apply for different gas specific gravities and operating scenarios. Comparing the experimental value of temperature and the values generated from each of the different correlation used, shows that the Towler and Mokhatab correlation (regarded herein as T\&M) showed a very high level of accuracy for all range of specific gravity and at temperatures below $60^{\circ} \mathrm{F}$.

Right, IJAR, 2018,. All rights reserved.

\section{Introduction:-}

With the ever increasing growth of oil and gas deep-water pipeline infrastructure, it is important to acknowledge, identify, and develop the critical relationships between gas hydrate and flow assurance. Gas hydrates pose one of the major flow assurance problems in natural gas production and processing, if not handled properly, they can become so big hence, and create operational difficulties that lead to undesirable and costly interruptions in gas production, field processing, and distribution [3].

Gas hydrates are ice-like structure formed form the chemical combination of natural gas (methane to iso-butane regarded as "hydrate formers") and water at a particular pressure and at temperatures above the freezing point of water. Contrary to general misconception, hydrates formation occurs not only in sweet gas but also in sour gas, common examples of other gases that are likely to form hydrates include: carbon dioxide, hydrogen sulphide, nitrogen, and oxygen gas. Hydrates can be classified into three basic structures based on the natural gas component contained in the hydrate former [9]; Structure I which allows the inclusion of both methane and ethane but not propane in its composition; Structure II which allows inclusion of propane and iso-butane in addition to methane and ethane and Structure $\mathrm{H}$ which accommodate higher quest molecules such as iso-pentane. 
Hydrates are generally formed under conditions of low temperature and high pressure, conditions which are easily met in subsea operations, thus, there is a very high tendency for hydrate formation in natural gas production flowlines and deep water transmission pipelines. Some other conditions which promote hydrate formation are: natural gas at or below its "dew point" with free water present, temperatures below the hydrate formation temperature for the natural gas composition and pressure being considered, high operating pressures which tend increase the "hydrate formation temperature", high velocity or agitation through piping or equipment e.g. across the choke [3]. The dew point is the temperature at which a particular stream of natural gas is in equilibrium with water vapour at a particular pressure, as such at temperatures below dew point the water vapour condenses to liquid. Hydrate formation temperature on the other hand is the temperature below which hydrates will start forming.

Preventing hydrate formation and its eventual removal accounts for about $70 \%$ of deep water flow assurance challenges [6]; the remaining 30\% deal with waxes, scale corrosion, and asphaltenes [5]. Hydrates plugging up a pipeline may cost the oil and gas industry in the excess of \$1million in terms of Non-Productive Time (NPT), aside the loss incurred due to known production, huge hydrate plugs can take a lot of time (days, weeks or even months) to completely dissociate safely, in addition, it will also require complex and very expensive process like pigging for plug removal [2]. Surface facilities such as compressors, flowlines, and heat exchangers can become damaged due to the formation of hydrates, thus, in order to optimize the cost of operating a natural gas production and or processing system it is important to prevent hydrate formation as much as possible.

The textbook method of combating the problem of hydrate formation is by ensuring that the conditions that would normally promote it are not met. Since the presence of water and the operating conditions in terms of temperature and pressure are two of the major elements in hydrate formation most prevention techniques are targeted towards them.

However, the first step towards an effective prevention strategy is the knowledge of the hydrate formation conditions - temperature at a specific pressure or pressure at a given temperature. The most appropriate method for determining this is by experimentally measuring hydrate formation at the temperature or pressure and gas composition of interest [10].

However, since gases are very sensitive to temperature and pressure changes, it is practically impossible to carry out an experiment for the limitless number of hydrate formation conditions for every distinct gas composition for which measurements are required, in addition, this experiments are time-consuming and expensive; hence, accurate prediction techniques for hydrate formation condition become desirable.

\section{Literature Review:-}

There are numerous methods available for predicting hydrate formation conditions. The popular ones are highlighted below:

\section{K-factor method}

Also referred to as the vapour-solid equilibrium ratio method, it was developed by Carson and Katz (1942), although additional data and charts have been reproduced since then. Prediction of hydrate formation temperature is carried out by using vapour-solid equilibrium constants. Katz et al reasoned that hydrates are the equivalent of solid solutions and are not mixed crystals. They postulated that hydrate formation conditions can be calculated from empirically determined vapour-solid equilibrium constants:

Where,

$$
\mathrm{K}_{\mathrm{s}}=\frac{\mathrm{y}_{\mathrm{i}}}{\mathrm{x}_{\mathrm{i}}}
$$

$\mathrm{K}_{\mathrm{s}}=$ vapour-solid equilibrium constant

$\mathrm{y}=$ mole fraction the ith hydrocarbon component in the gas on a water-free basis

$\mathrm{x}_{\mathrm{s}}=$ mole fraction of the ith hydrocarbon component in the solid on a water-free basis.

The vapour-solid equilibrium constant is determined experimentally, for nitrogen and components heavier than butane, the equilibrium constant is taken as infinity. Theoretically, this assumption is not correct, but from a practical point of view it provides acceptable engineering results.

In addition, the hydrate formation condition should satisfy: 


$$
\sum_{i=1}^{n} \frac{y_{i}}{K_{i}}=1
$$

This procedure is analogous to the dew point calculation for complex gas mixtures, $\mathrm{K}$ charts for methane, ethane, propane, i-butane, n-butane, carbon dioxide, hydrogen sulphide are provided in the appendix. It provides accurate and reliable results for sweet natural gases (the presence of non-hydrocarbon gases most especially carbon dioxide, hydrogen sulphide and nitrogen may cause inaccurate results) and has been proven to be appropriate up to about 1000 psia. However, the calculation is a rigorous iteration and the solid formation point will determine when equation 2 is satisfied.

\section{Gas gravity method:}

developed by Katz (1945), it can be used when the composition of the gas stream is not known [4]. Relative to the $\mathrm{K}$-factor method, it provides an approximate and easy-to-use technique of predicting hydrate formation conditions. The plot presents a way of relating the hydrate formation pressure and temperature with gas gravity defined as the apparent molecular weight of a gas mixture divided by that of air which is 28.96 [1].

The chart was generated from a limited amount of experimental data and a more substantial amount of calculations based on the K-value method. A statistical accuracy analysis reported by Sloan showed that his method is not accurate [11]. For the same gas gravity, different mixtures may lead to about $50 \%$ error in the predicted pressure. As a first step to predict hydrate formation temperature, an appropriate equation representing the Katz gravity chart was developed by Towler and Mokhatab (2005):

$\mathrm{T}={ }^{0} \mathrm{~F}, \mathrm{P}=\mathrm{psia}$

$$
\mathrm{T}=13.47 \ln (\mathrm{P})+34.27 \ln \left(\gamma_{\mathrm{g}}\right)-1.675\left[\ln (\mathrm{P}) \times \ln \left(\gamma_{\mathrm{g}}\right)\right\rfloor-20.35
$$

\section{Hammerschmidt Correlation}

Hammerschmidt (1934) developed the first and simplest correlation for the prediction of hydrate formation conditions.

$$
\mathrm{T}=8.9 \mathrm{P}^{0.285}
$$

Transforming (4) to pressure explicit form:

$$
\mathrm{P}=\left(\frac{\mathrm{T}}{8.9}\right)^{3.509}
$$

With Temperature in ${ }^{\circ} \mathrm{F}$, and Pressure in psia.

\section{Makogon Correlation}

This simple hand calculation for predicting hydrate formation was developed by Yuri F. Makogon (1981). This was further modified by Ahmed A. Elgibaly \& Ali M. Elkamel (1997). Makogon presented various expressions for the relationship between hydrate formation pressure and temperature in pure components and selected natural gas stream. All of the expressions follow the same form, and based on experimental evidence the following equation describes the relationship between hydrate formation pressure and temperature:

Where,

$$
\ln \mathrm{P}=0.0497\left(\mathrm{~T}+\mathrm{kT}^{2}\right)+\beta
$$

$\mathrm{P}=$ pressure $(\mathrm{MPa})$, and $\mathrm{T}=$ Temperature $\left({ }^{\circ} \mathrm{C}\right)$

$\beta$ and $\mathrm{k}$ can be obtained graphically in a separate plot with gas specific gravity as the independent variable. However, constants $\beta$ and $\mathrm{k}$ can be calculated as a function of gas gravity thus,

$$
\begin{aligned}
& \beta=2.681-3.811 \gamma+1.679 \gamma^{2} \\
& k=-0.006+0.011 \gamma+0.011 \gamma^{2}
\end{aligned}
$$

Equation 6 applies to sweet natural gas and is only valid for temperatures within $0-25^{\circ} \mathrm{C}$. Makogon's original work was modified by Carroll (2000):

$$
\ln \mathrm{P}=0.0497\left(\mathrm{~T}+\mathrm{kT}^{2}\right)+\beta-1
$$

Although not developed for sour gases, it is included in order to determine the degree of uncertainty when applied to sour gases [12]. It is a simple method, and can serve as a guide to make an initial approximation of hydrate formation conditions. 


\section{Berge correlation}

Berge (1986) developed temperature explicit equations which calculate the hydrate formation temperature for a given pressure at particular gas gravity. The equations are:

$\mathrm{T}=$

$$
\text { For } 0.555 \leq \gamma_{\mathrm{g}} \leq 0.58 \text { : }
$$

$$
\begin{aligned}
-96.03+25.37 & \ln P \\
& -0.64(\ln P)^{2}+\frac{\gamma_{g}-0.555}{0.025}\left[80.61 P+1.16 \times 10^{4} \frac{1}{(P+599.16)}-(-96.03\right. \\
& \left.\left.+25.37 \ln P-0.64(\ln P)^{2}\right)\right]
\end{aligned}
$$

For $0.58 \leq \gamma_{\mathrm{g}} \leq 1.0$ :

$$
\frac{\left[80.61 \mathrm{P}-2.1 \times 10^{4}-1.22 \times 10^{3} \frac{1}{\left(\gamma_{\mathrm{g}}-0.535\right)}-\left(1.23 \times 10^{4}+1.71 \times 10^{3} \frac{1}{\left(\gamma_{\mathrm{g}}-0.509\right)}\right]\right.}{\left[\mathrm{P}-\left(-260.42-\frac{15.18}{\gamma_{\mathrm{g}}-0.535}\right)\right](10)}
$$

With temperature recorded in ${ }^{\circ} \mathrm{F}$ and pressure in psia.

\section{Kobayashi's Correlation}

Based on Katz's gas gravity curves, Kobayashi et al (1987) developed a correlation to predict hydrate formation temperature given as equation 11 below:

$$
\begin{aligned}
\mathrm{T}=1 /\left[\mathrm{A}_{1}+\mathrm{A}_{2}\right. & \left(\ln \gamma_{\mathrm{g}}\right) \\
& +\mathrm{A}_{3}(\ln \mathrm{P})+\mathrm{A}_{4}\left(\ln \gamma_{\mathrm{g}}\right)^{2} \\
& +\mathrm{A}_{5}\left(\ln \gamma_{\mathrm{g}}\right)(\ln \mathrm{P})+\mathrm{A}_{6}(\ln \mathrm{P})^{2}+\mathrm{A}_{7}\left(\ln \gamma_{\mathrm{g}}\right)^{3}+\mathrm{A}_{8}\left(\ln \gamma_{\mathrm{g}}\right)^{2}(\ln \mathrm{P})+\mathrm{A}_{9}\left(\ln \gamma_{\mathrm{g}}\right)(\ln \mathrm{P})^{2}+\mathrm{A}_{10}(\ln \mathrm{P})^{3} \\
& \left.+\mathrm{A}_{11}\left(\ln \gamma_{\mathrm{g}}\right)^{4}+\mathrm{A}_{12}\left(\ln \gamma_{\mathrm{g}}\right)^{3}(\ln \mathrm{P})+\mathrm{A}_{13}\left(\ln \gamma_{\mathrm{g}}\right)^{2}(\ln \mathrm{P})^{2}+\mathrm{A}_{14}\left(\ln \gamma_{\mathrm{g}}\right)(\ln \mathrm{P})^{3}+\mathrm{A}_{15}(\ln \mathrm{P})^{4}\right]
\end{aligned}
$$

Table 1:-List of Constants in the Kobayashi Correlation

\begin{tabular}{|l|l|l|l|}
\hline Constant & Value & Constant & Value \\
\hline $\mathrm{A}_{1}$ & $2.7707715 \times 10^{-3}$ & $\mathrm{~A}_{9}$ & $-2.3729181 \times 10^{-4}$ \\
\hline $\mathrm{A}_{2}$ & $-2.782238 \times 10^{-3}$ & $\mathrm{~A}_{10}$ & $-2.6840758 \times 10^{-5}$ \\
\hline $\mathrm{A}_{3}$ & $-5.649288 \times 10^{-4}$ & $\mathrm{~A}_{11}$ & $4.6610555 \times 10^{3}$ \\
\hline $\mathrm{A}_{4}$ & $-1.298593 \times 10^{-3}$ & $\mathrm{~A}_{12}$ & $5.5542412 \times 10^{-4}$ \\
\hline $\mathrm{A}_{5}$ & $1.407119 \times 10^{-3}$ & $\mathrm{~A}_{13}$ & $-1.4727765 \times 10^{-5}$ \\
\hline $\mathrm{A}_{6}$ & $1.785744 \times 10^{-4}$ & $\mathrm{~A}_{14}$ & $1.3938082 \times 10^{-5}$ \\
\hline $\mathrm{A}_{7}$ & $1.130284 \times 10^{-3}$ & $\mathrm{~A}_{15}$ & $1.4885010 \times 10^{-6}$ \\
\hline $\mathrm{A}_{8}$ & $5.9728235 \times 10^{-4}$ & & \\
\hline
\end{tabular}

Equation 4 is accurate for temperatures up to $62^{\circ} \mathrm{F}$, for pressures up to $1500 \mathrm{psia}$, and gas gravity up to 0.9 . Its accuracy becomes questionable above these conditions.

\section{Motiee correlation}

Mottie (1991) used a regression method to determine coefficients that would correlate temperature, pressure and specific gravity. The equations are:

$\log P=a_{1}+a_{2} T+a_{3} T+a_{4} \gamma_{g}+a_{5} \gamma_{g}^{2}+a_{6} T \gamma_{g}$
$T=b_{1}+b_{2} \log P+b_{3}(\log P)^{2}+b_{4} \gamma_{g}+b_{5} \gamma_{g}^{2}+b_{6} \gamma_{g} \log P$

Table 2:-Constants for Temperature Explicit Motiee Correlation ( $\mathrm{P}$ in psia and $\mathrm{T}$ in $\left.{ }^{\circ} \mathrm{F}\right)$

\begin{tabular}{|l|l|l|l|}
\hline Constant & Value & Constant & Value \\
\hline $\mathrm{b}_{1}$ & -238.24469 & $\mathrm{~b}_{4}$ & 349.473877 \\
\hline $\mathrm{b}_{2}$ & 78.99667 & $\mathrm{~b}_{5}$ & -150.854675 \\
\hline $\mathrm{b}_{3}$ & -5.352544 & $\mathrm{~b}_{6}$ & -27.604065 \\
\hline
\end{tabular}




\section{Østergaard et al correlation:-}

Like many of the other hand calculation methods, the correlation developed by Østergaard et al (2000) is based on gas gravity. It is applicable for a range of fluids, from black oils to lean natural gas. It differs from many of the other available methods by the fact that it accounts for sour gas in $\mathrm{CO}_{2}$, and inert gas in $\mathrm{N}_{2}$. However, the use of this model is based on the knowledge of the molar ratio of hydrate to non-hydrate formers - this requires a full analysis of the gas mixture. The correlation was not utilized in this study.

The most recent correlation that has been applied in the prediction of hydrate formation conditions is Bahadori and Vuthalaru (2009), however, because of the large number of input required and its mathematical complexity it was not made use of in this study.

\section{Methodology:-}

To predict hydrate formation, there is a need to perform hydrate modelling, of which the prediction can be gotten from hydrate formation linear plot as a function of both temperature and pressure of the gas composition. The methodology employed in this study was to develop a very interactive and easy-to-use computer tool for determining hydrate formation conditions. Correlations that were incorporated into the tool include Towler and Mokhatab, Hammerschmidt, Makogon, Berge, Kobayashi, and Motiee. The tool needs the required data for each of the different correlation as input; it either predicts temperature given pressure and specific gravity and pressure given temperature and specific gravity. In cases where the specific gravity of the gas is not known, the composition of the gas can be inputted into the tool.

Data validation was done by using the R-squared method to compare the experimental results and calculated results.

\section{Results and Discussion:-}

Table 4:-Comparison of Results for 0.555 gravity gas

\begin{tabular}{|l|l|l|l|l|l|l|}
\hline \multicolumn{2}{|c|}{ Temperature explicit correlations (Temperature is given in ${ }^{\mathbf{0}} \mathbf{F}$ ) } \\
\hline Pressure (psia) & Experimental & T \& M & Hammerschmidt & Berge & Motiee & Kobayashi \\
\hline 458 & 35 & 48.04 & 51.02 & 35.38 & 40.78 & 47.63 \\
\hline 600 & 40 & 51.95 & 55.10 & 40.07 & 44.84 & 40.75 \\
\hline 800 & 45 & 56.11 & 59.81 & 44.96 & 48.99 & 34.67 \\
\hline
\end{tabular}

Table 5:-Comparison of Results for 0.6 gravity gas

\begin{tabular}{|l|l|l|l|l|l|l|}
\hline \multicolumn{2}{|c|}{ Temperature explicit correlations (Temperature is given in ${ }^{\mathbf{0}} \mathbf{F}$ ) } \\
\hline Pressure (psia) & Experimental & T \& M & Hammerschmidt & Berge & Motiee & Kobayashi \\
\hline 250 & 40 & 41.24 & 42.93 & -68.16 & 36.07 & 68.85 \\
\hline 480 & 50 & 50.59 & 51.71 & -33.03 & 46.05 & 46.48 \\
\hline 980 & 60 & 60.81 & 63.37 & 5.52 & 56.00 & 31.07 \\
\hline 2625 & 70 & 74.93 & 83.92 & 45.12 & 68.03 & 18.69 \\
\hline
\end{tabular}

Table 6:-Comparison of Results for 0.65 gravity gas

\begin{tabular}{|l|l|l|l|l|l|l|}
\hline Temperature explicit correlations (Temperature is given in $\left.{ }^{\mathbf{0}} \mathbf{F}\right)$ & Hammerschmidt & Berge & Motiee & Kobayashi \\
\hline Pressure (psia) & Experimental & T \& M & Hammen & -93.88 & 27.51 & 116.21 \\
\hline 110 & 30 & 31.59 & 33.98 & -31.44 & 47.44 & 52.66 \\
\hline 390 & 50 & 49.56 & 48.74 & 44.72 & 68.67 & 21.14 \\
\hline 2050 & 70 & 73.11 & 78.21 & &
\end{tabular}

Table 7:-Comparison of Results for 0.7 gravity gas

Temperature explicit correlations (Temperature is given in ${ }^{\circ} \mathbf{F}$ )

\begin{tabular}{|l|l|l|l|l|l|l|}
\hline Pressure (psia) & Experimental & T \& M & Hammerschmidt & Berge & Motiee & Kobayashi \\
\hline 120 & 35 & 34.77 & 34.83 & -84.61 & 33.40 & 110.17 \\
\hline 340 & 50 & 49.43 & 46.87 & -32.12 & 49.23 & 57.27 \\
\hline 690 & 60 & 59.38 & 57.34 & 5.73 & 58.74 & 37.82 \\
\hline 3400 & 75 & 81.82 & 90.34 & 59.81 & 76.45 & 16.50 \\
\hline
\end{tabular}


Table 8:-Comparison of Results for 0.8 gravity gas

\begin{tabular}{|l|l|l|l|l|l|l|}
\hline \multicolumn{2}{|l|}{ Temperature explicit correlations (Temperature is given in ${ }^{\mathbf{0}} \mathbf{F}$ ) } \\
\hline Pressure (psia) & Experimental & T \& M & Hammerschmidt & Berge & Motiee & Kobayashi \\
\hline 72 & 30 & 31.21 & 30.11 & -97.45 & 32.03 & 153.24 \\
\hline 280 & 50 & 50.01 & 44.34 & -35.48 & 52.01 & 64.59 \\
\hline 1700 & 70 & 74.98 & 74.14 & 46.22 & 72.79 & 23.27 \\
\hline
\end{tabular}

Table 9:-Comparison of Results for 0.9 gravity gas

\begin{tabular}{|l|l|l|l|l|l|l|}
\hline \multicolumn{1}{|c|}{ Temperature explicit correlations (Temperature is given in ${ }^{\mathbf{0}} \mathbf{F}$ ) } \\
\hline Pressure (psia) & Experimental & T \& M & Hammerschmidt & Berge & Motiee & Kobayashi \\
\hline 110 & 40 & 40.18 & 33.98 & -78.03 & 42.33 & 117.03 \\
\hline 230 & 50 & 50.25 & 41.93 & -42.25 & 52.13 & 73.08 \\
\hline 2600 & 75 & 83.35 & 83.69 & 58.09 & 76.60 & 18.79 \\
\hline
\end{tabular}

Table 10:-Comparison of Result for 1.0 gravity gas

\begin{tabular}{|l|l|l|l|l|l|l|}
\hline \multicolumn{1}{|l|}{ Temperature explicit correlations (Temperature is given in ${ }^{\mathbf{0}} \mathbf{F}$ ) } \\
\hline Pressure (psia) & Experimental & T \& M & Hammerschmidt & Berge & Motiee & Kobayashi \\
\hline 60 & 35 & 34.80 & 28.59 & -97.91 & 34.83 & 172.65 \\
\hline 195 & 50 & 50.68 & 40.00 & -48.53 & 50.00 & 81.11 \\
\hline 440 & 60 & 61.64 & 50.44 & -5.37 & 58.83 & 49.20 \\
\hline
\end{tabular}

Comparing the experimental value of temperature and the values generated from each of the different correlation used: Berge and Kobayashi equation gave really erroneous results in most cases - as at the time of carrying out this research, the constants in Kobayashi's correlation seem to be wrong. However, as an exception they gave very close results for gas of specific gravity 0.555 . At specific gravity of 0.555 , results obtained from Hammerschmidt correlation were different from the experimental value, but as specific gravity increases (from 0.6 to 0.8 ) and at temperatures below $60^{\circ} \mathrm{F}$, the calculated hydrate formation temperatures were quite close to the experimentally obtained results.

Results obtained from Motiee correlation showed a great amount of accuracy at high specific gravities and temperatures above $60^{\circ} \mathrm{F}$, most especially at specific gravity of 1.0, for low specific gravity and temperatures below $60^{\circ} \mathrm{F}$ results obtained with Motiee correlation were moderately accurate.

The Towler and Mokhatab correlation (regarded herein as $\mathrm{T} \& \mathrm{M}$ ) showed a very high level of accuracy for all range of specific gravity and at temperatures below $60^{\circ} \mathrm{F}$.

A summary of the data validation for each of the correlation is given below.

\section{R-squared values for $\mathbf{0 . 5 5 5}$ gravity gas}

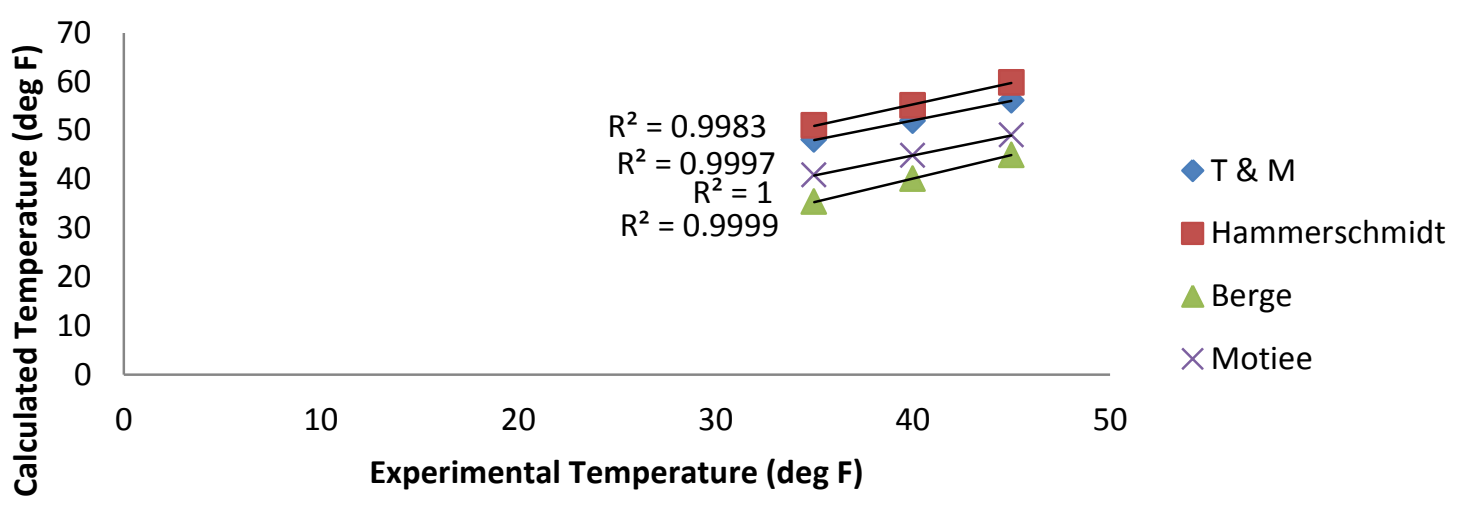

Figure 1:-Cross plot of experimental and predicted values for 0.555 specific gravity gas 


\section{R-squared values for $\mathbf{0 . 6}$ gravity gas}

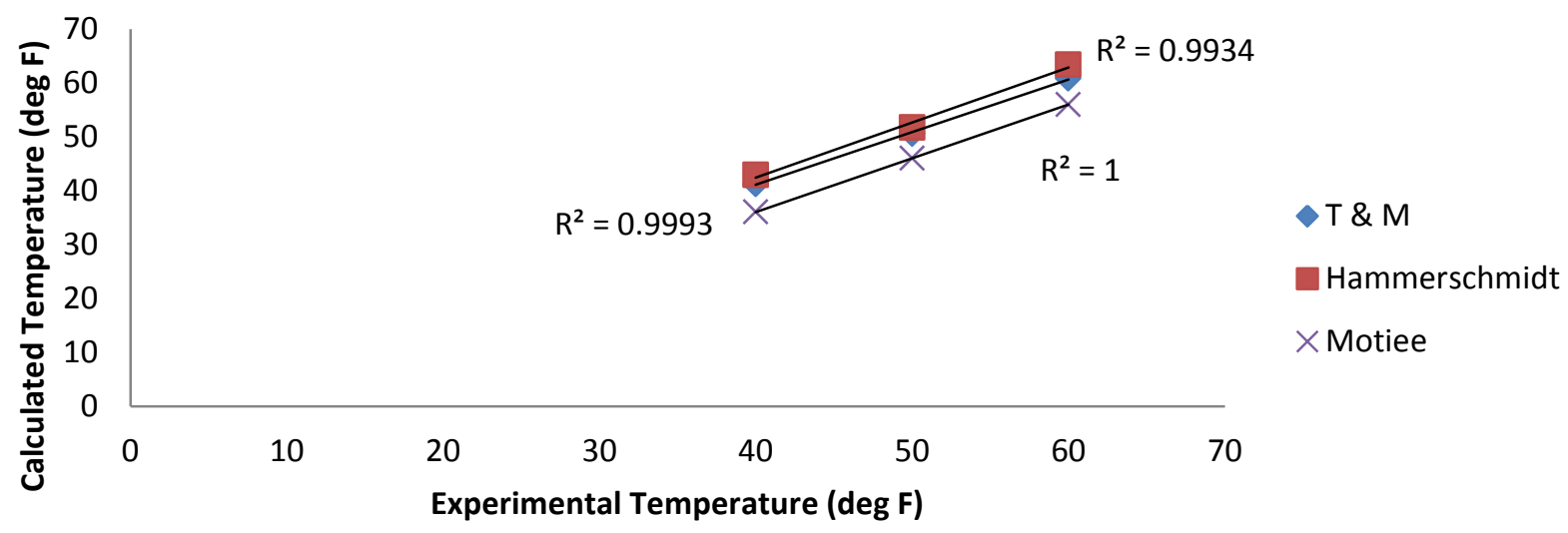

Figure 2:-Cross plot of experimental and predicted values for 0.6 specific gravity gas

\section{R-squared values for 0.65 gravity gas}

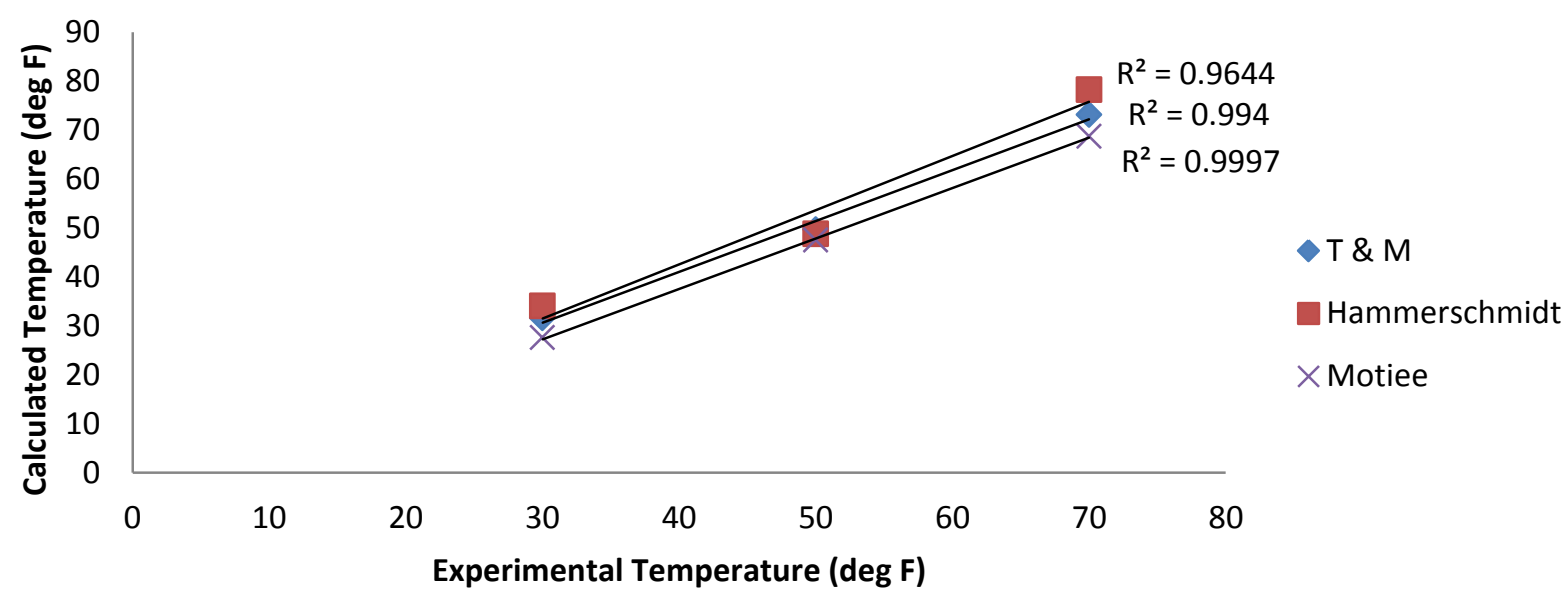

Figure 3:-Cross plot of experimental and predicted values for 0.65 specific gravity gas

\section{R-squared values for $\mathbf{0 . 7}$ gravity gas}

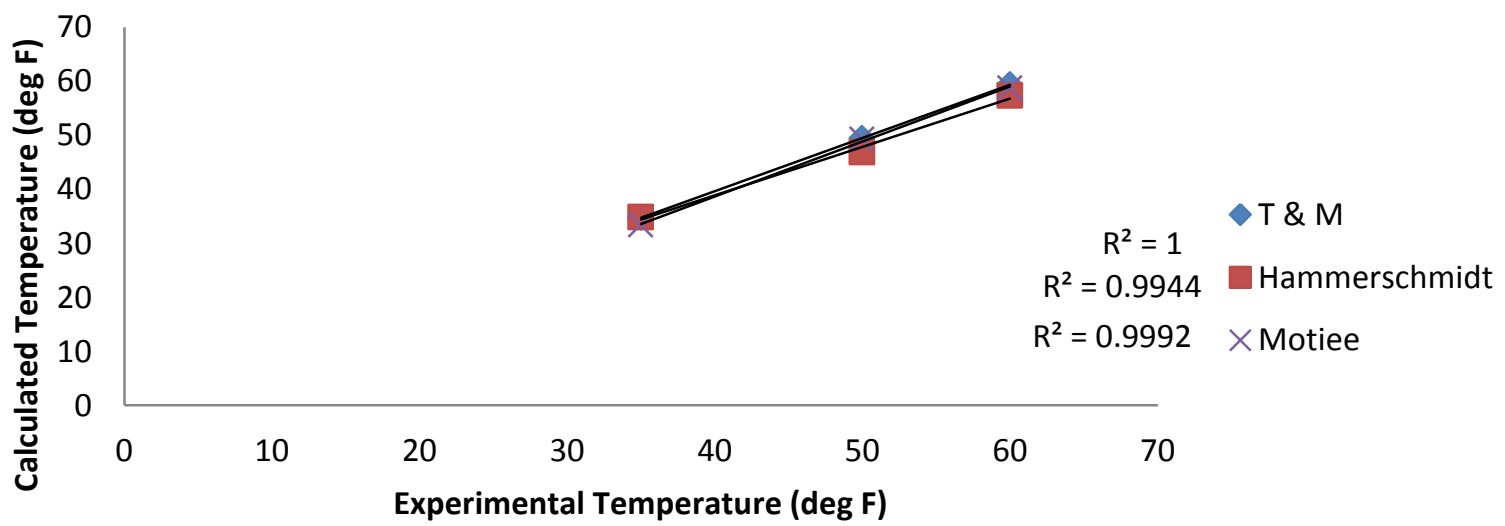

Figure 4: Cross plot of experimental and predicted values for 0.7 specific gravity gas 


\section{R-squared values for $\mathbf{0 . 8}$ gravity gas}

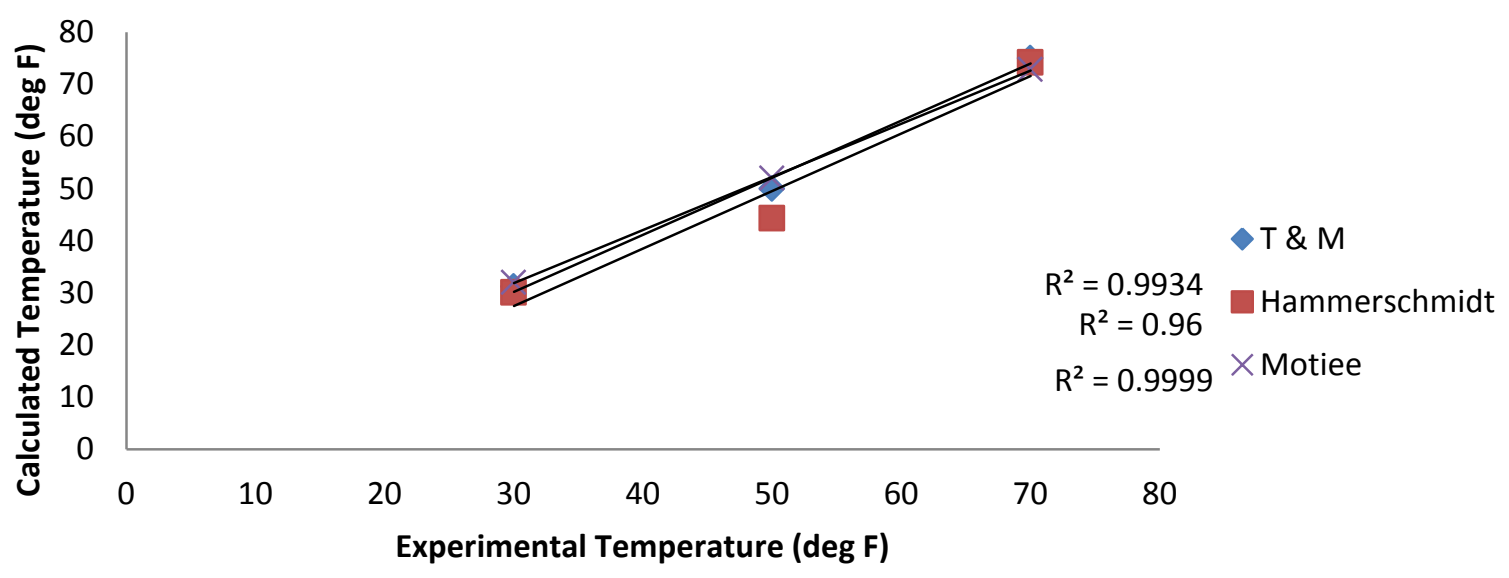

Figure 5:-Cross plot of experimental and predicted values for 0.8 specific gravity gas

\section{R-squared values for $\mathbf{0 . 9}$ gravity gas}

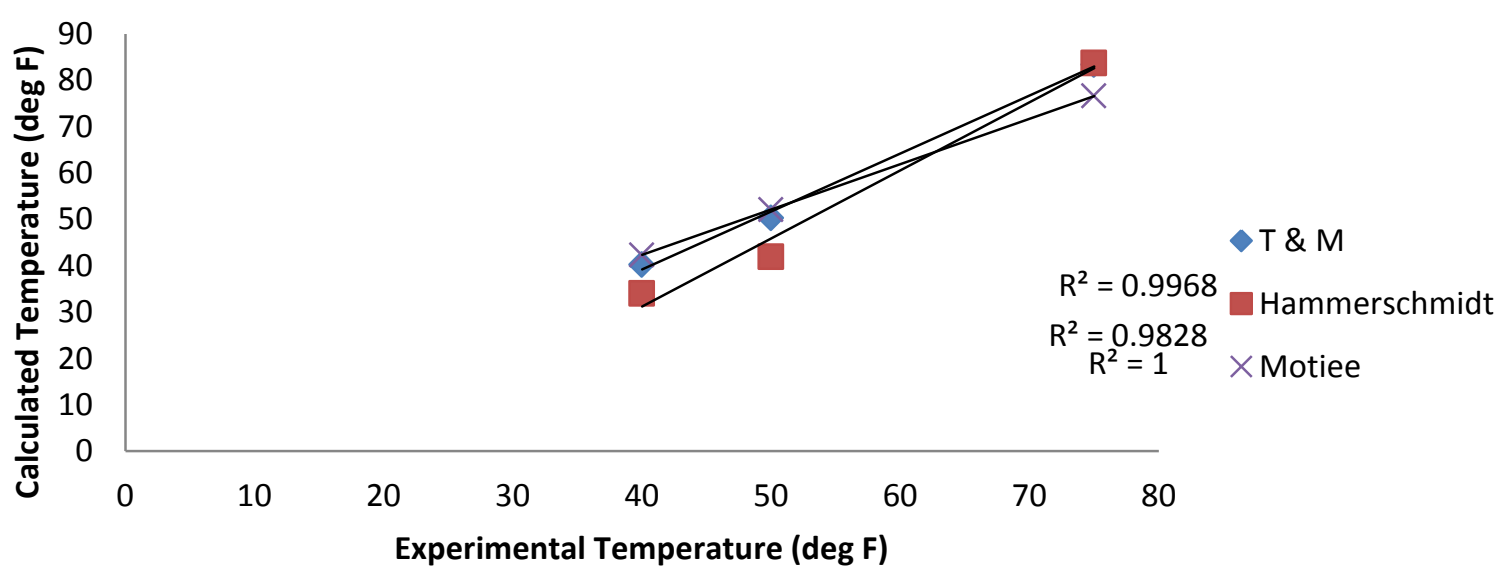

Figure 6:-Cross plot of experimental and predicted values for 0.9 specific gravity gas

\section{R-squared values for 1.0 gravity gas}

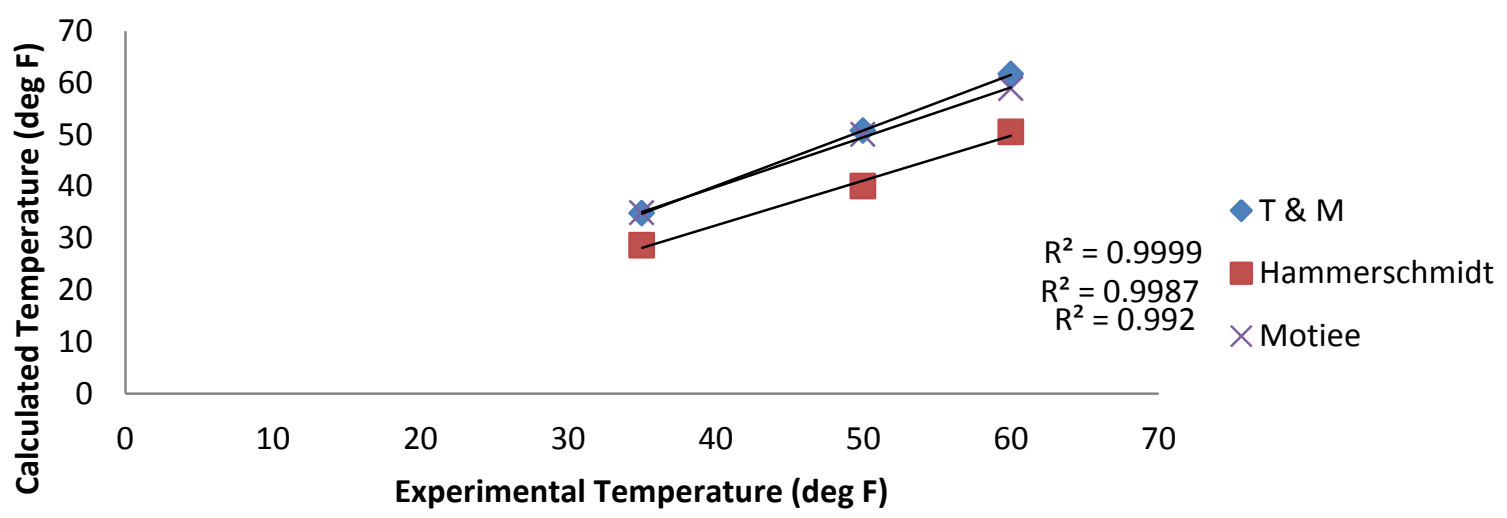

Figure 7:-Cross plot of experimental and predicted values for 0.9 specific gravity gas 


\section{Conclusion and Recommendation:-}

Prediction of hydrate formation condition using correlations is still a widely used practice. Accurate assessment of the risks based on accurate estimated predictions is essential in deep-water production pipeline conceptual design and operations. This study herein developed a simple computer modelling tool to aid estimation of the hydrate formation condition of a sample fluid using variety of hydrate prediction correlations. The tool uses the required data available as input for each known correlation to calculate and predict the hydrate formation temperature and pressure profile for any given input.

Having determined the hydrate formation conditions of the natural gas stream, it is expedient to put strategies that will prevent or reduce the possibility of hydrate formation in place, the different methods for determining inhibitor injection rate should also be included in this tool as a further study.

\section{References:-}

1. Ahmed A. E., \& Ali M. E., (1998), "A New Correlation for Predicting Hydrate Formation Conditions For Various Gas Mixtures and Inhibitors" College of Engineering and Petroleum, University of Kuwait, Kuwait.

2. Atilhan, M., Aparicio, S., Benyahia, F. \& Deniz, E. (2012), "Natural Gas Hydrates, Advances in Natural Gas Technology", Dr. Hamid Al-Megren (Ed.), ISBN: 978-953-51-0507-7, InTech.

3. Ikoku, C.U., (1992), "Natural Gas Production Engineering", Pennsylvania State University. Krieger Publishing Company, Malabar, Florida. pp. 137, 139

4. Mohammad, M. G., (2012), "Initial Estimation of Hydrate Formation Temperature of Sweet Natural Gases Based on New Empirical Correlation" Journal of Natural Gas Chemistry 21(2012) 508-512

5. Ogezo S. O. (2014), "Effects of Hydrates Formation on Gas Pipelines (A Case Study on Eriemu Field)", University of Salford.

6. Petrowiki, "Preventing formation of hydrate plugs"

7. Presentation titled: "Gas hydrates in Gas Pipeline Transmission", Thermodynamic Property Methods, www.profsite.um.ac.ir

8. Presentation titled: "Gas hydrates in Gas Pipeline Transmission", Thermodynamic Property Methods, www.profsite.um.ac.ir

9. Salam, K. K., Arinkoola, A. O., Araromi, D. O. \& Ayansola Y. E. (2013); "Prediction of Hydrate Formation Conditions in Gas Pipelines", International Journal of Engineering Sciences, 2(8) August 2013, Pages: 327-331.

10. Seyed, M. H., Vafaei, M., Mohamadi, A., \& Izadpanah, A. A. (2011), "Development of New Empirical Correlation for Predicting Hydrate Formation Conditions" paper presented at the 7th International Conference on Gas Hydrates (ICGH 2011), Edinburgh, Scotland, United Kingdom, July 17-21, 2011.

11. Sloan, E. D. (1984), "Phase Equilibrium of Natural Gas Hydrates", Proceedings of $63^{\text {rd }}$ GPA Convention, pp. 163-169.

12. Torbjor, (2011), "Dissociation Pressure of Natural Gas Hydrate" TPG4510 Petroleum Production Specialization Project submitted to the Department of Petroleum Engineering and Applied Geophysics, NTNU (December, 2011). Pg. 18 